\title{
UNSTEADY KINEMATICS OF MULTISTAGE AXIAL COMPRESSOR SHROUDED CAVITY FLOW
}

\author{
Jaehyoung Lee \\ Hanwha Power Systems \\ jhyoung.lee@hanwha.com \\ Seongnam, Gyunggi-do, Republic of Korea \\ Hyoun-Woo Shin \\ hwk50shin@gmail.com \\ Cincinnati, Ohio, United States of America
}

\author{
Sungkyung Lim \\ Hyundai Motor Company \\ buhaw17@gmail.com \\ Hwaseong, Gyunggi-do, Republic of Korea
Sungryong Lee
Doosan Heavy Industries
sungryong.lee@doosan.com
Changwon, Gyungsangnam-do, Republic of
Korea

\author{
Keibyeong Lee \\ Konkuk University \\ blue07716@gmail.com \\ Seoul Metropolitan City, Seoul, \\ Republic of Korea
}

\author{
Hongsung Moon \\ Samsung Electronics \\ mhs3395@snu.ac.kr \\ Suwon, Gyunggi-do, \\ Republic of Korea
}

\author{
Seung Jin Song \\ Seoul National University \\ sjsong@snu.ac.kr \\ Seoul Metropolitan City, Seoul, \\ Republic of Korea
}

\begin{abstract}
An experimental investigation has been performed in a low-speed shrouded multistage axial compressor to investigate the impact of mainstream flow on unsteady shrouded cavity flow. A single $45^{\circ}$ slanted hot-wire has been used to obtain the ensemble-averaged three-dimensional velocity vectors inside the upstream and downstream cavities of $3^{\text {rd }}$ stage stator, which are identical to known shrouded stator cavity flow structures. The mechanism of the unsteadiness inside shrouded stator cavities is analysed; intermittent radial movements created by the superposition of $2^{\text {nd }}$ stage stator and $3^{\text {rd }}$ stage rotor wakes suppress local ingress due to the pressure side of $3^{\text {rd }}$ stage rotor, creating pairs of local ingress-egress inside the upper cavity of $3^{\text {rd }}$ stage shrouded stator. In addition, the variation of hubside velocity downstream of $3^{\text {rd }}$ stage stator alters the position of recirculation inside downstream $3^{\text {rd }}$ stage stator cavity.
\end{abstract}

\section{INTRODUCTION}

Compared with cantilevered stator configuration, the flow in stators shrouded at the hub shows the hubside corner separation at the stator suction side (SS), increasing the hubside loss and blockage (Swoboda et al., 1998; Campobasso et al., 1999; Lange et al., 2010). About $\sim 20 \%$ of hubside blockage created by hubside corner separation was reported, compared with about $\sim 5 \%$ at stator midspan (Joslyn and Dring, 1985).

In addition, the labyrinth seal leakage flow of shrouded stator emerges from the upper cavity of shrouded stator, further reducing the hubside momentum; and the increased mass flow rate or reduced tangential velocity of labyrinth seal leakage flow further degrades compressor performances (Wellborn and Okiishi, 1999; Wellborn, 1999; Demargne and Longley, 2000; Kim et al., 2012; Marty and Aupoix, 2012; Schrapp et al., 2019). The low-momentum labyrinth seal leakage flow heads towards the stator pressure side (PS), then to the stator passage suction side (SS) due to the PS-SS pressure gradient inside the stator passage (Wellborn and Okiishi, 1996; Kim et al., 2012), This labyrinth seal leakage flow widens the width of the hubside low-momentum region and creates additional vortical structure nearby hubside corner separation. (Wellborn, 2001; Demargne and Longley, 2000; Fröebel et al., 2010; Kim et al., 2012).

The reduced momentum of labyrinth seal leakage flow are created by the vortical structures inside the cavities between the labyrinth seals and shroud (Heidegger et al., 1996; Wellborn, 2001; Kim et al., 2012; Childs, 2004; Denecke et al., 2005; Flores and Seume, 2014; Chupp et al., 2006; Pfau, 2013). The magnitude of vortical structures and loss vary 


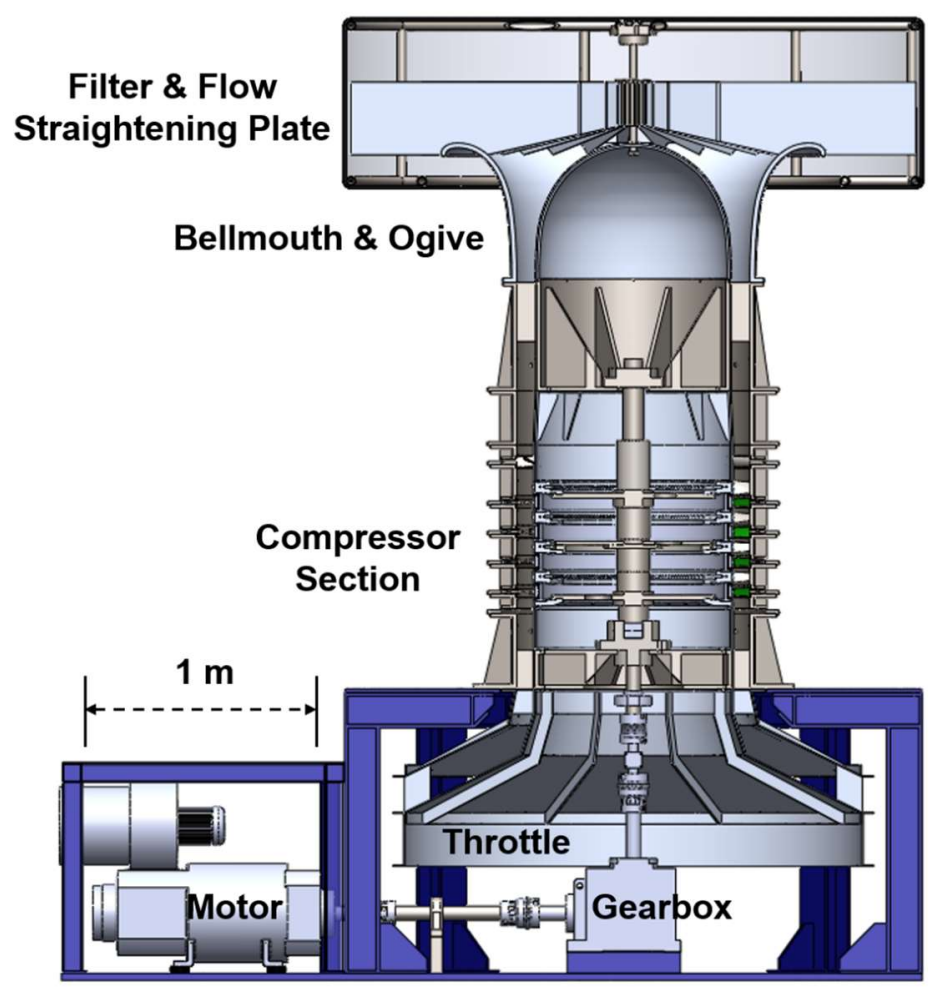

Figure 1. Schematic of SNU Compressor

depending on geometry (Heidegger et al., 1996). In addition, pitchwise variation of radial velocity inside cavities are observed due to potential effect of downstream stator leading edge and upstream blade wakes (Wellborn, 2001; Kim et al., 2012). Furthermore, the kinematics of flow in axial compressor is inherently unsteady by the relative motions between rotor and stator. The transportation of rotor wake into the downstream stator passage creates unsteady stator passage flow (Smith, 1966; Kerrebrock and Mikolajczak, 1970; Valkov and Tan, 1999; Mailach et al., 2008). Previous study (Wellborn, 2001) has found unsteadiness in velocity and local transient ingress/egress of upstream/downstream cavity flow of shrouded stators. Thus, it is expected that the unsteady variation of shrouded cavity flow affects the performances of shrouded axial compressor, which remains unanswered.

Therefore, the interaction between the cavity flow and mainstream flow of shrouded axial compressor should be investigated to reflect its impact on compressor performances. As a first step, the impact of mainstream flow on unsteady shrouded cavity flow will be discussed experimentally in this study, focusing on the unsteady kinematics of shrouded cavity flow.

\section{METHODOLOGY}

The present study has been conducted in a low-speed four repeating-stage shrouded axial compressor installed at Turbomachinery Laboratory, Seoul National University (Figure 1). It is an open-type axial compressor operated by a 55 kW DC motor. The ingested flow passes through a circular filter screen, an upstream bellmouth, and an ogive to reach the four-stage compressor section and exits the compressor via a downstream throttle. The blades have been designed by Doosan Heavy Industries \& Construction, and the compressor is powered by a 55-kW DC motor and a gearbox. Parameters of the SNU Compressor are summarized in Table. 1, and the details of the SNU compressor can be found in Lee (2019).

Measurements have been conducted at $\phi=0.355, \psi=1.292$. Three-dimensional unsteady velocities have been measured at six planes (Planes 3.5a, 3.5b, 3.5c and Planes 4.0a, 4.0b, 4.0c), ranging from $-20 \%$ to $-2 \%$ span (Planes 3.5a, 3.5c, 4.0a, $4.0 \mathrm{c}$ ) and $-20 \%$ to $50 \%$ span (Planes $3.5 \mathrm{~b}$ and $4.0 \mathrm{~b}$ ) to measure the three-dimensional velocity distribution inside shrouded cavities and mainstream flow upstream and downstream of $3^{\text {rd }}$ stage stator. The stator shroud has three-knife labyrinth seals (Figure 2). 


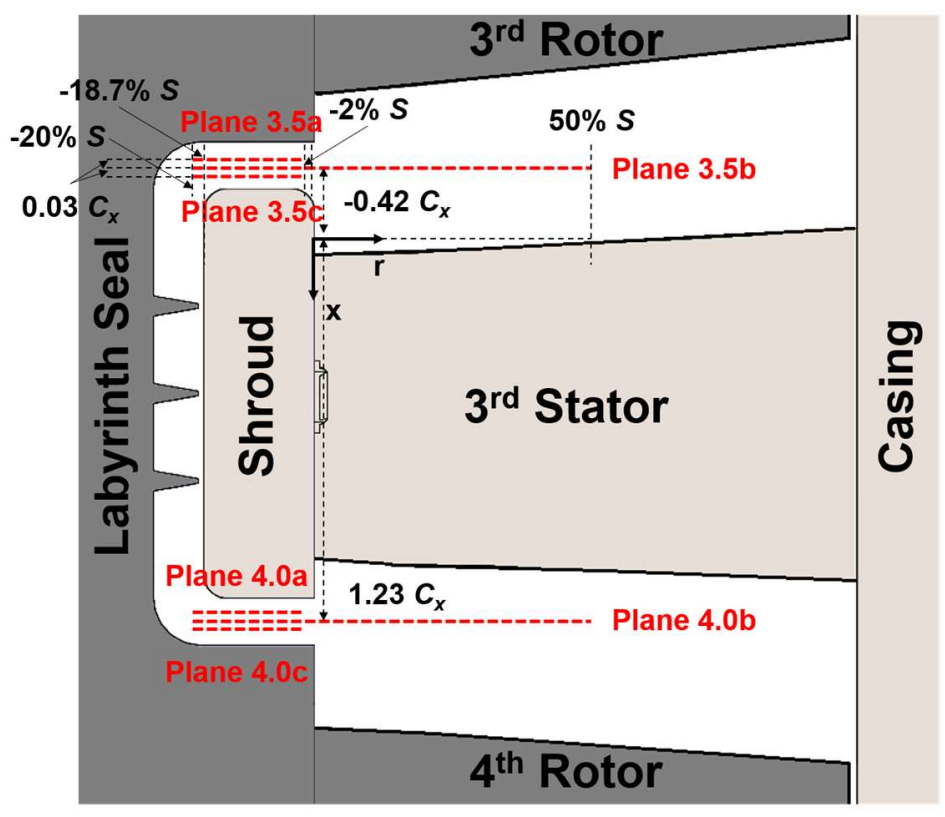

Figure 2 Measuring Planes and Locations

Radial and circumferential measurements have been performed using a single-element $45^{\circ}$ slanted hot-wires (Dantec Dynamics, 55P12), with a prong diameter $2.5 \%$, and wire length $1.67 \%$ of the passage span. Three measurements have been performed at a single measurement point at three different sensor yaw angle intervals of $40^{\circ}$. These raw-voltage signals have been acquired at known azimuthal rotor orientations using simultaneously collected encoder (Baumer, HOG14) signals. These signals have been collected by a DAQ board (National Instruments, PXI-4492) at a sampling rate of $200 \mathrm{kHz}$ (note that the blade passing frequency of the compressor is $866.67 \mathrm{~Hz}$ ), and low-pass filtered with cut-off frequency $100 \mathrm{kHz}$ to avoid alias. Approximately 80 signals have been obtained per single timestep, single yaw angle, at a given measuring point. The signals have been phase-locked ensemble-averaged and converted into velocity vectors using the technique of Shin et al. (1994). The root-mean square of collected raw-voltage is on average $1.21 \%$ of ensembleaveraged raw voltage signals. Uncertainties (with 95\% confidence interval) of $6.67 \%$ accuracy for the $U$ and $1.5^{\circ}$ for flow angle are obtained (Coleman and Steele, 2009).

\begin{tabular}{|c|c|}
\hline Parameters & Numbers \\
\hline Re $\left(C U_{t} / v\right)$ & 195,500 \\
\hline Design RPM & 1,000 \\
\hline$\dot{m}_{\mathrm{d}}$ & $5 \mathrm{~kg} / \mathrm{s}$ \\
\hline$\phi_{d}$ & 0.355 \\
\hline$\psi_{d}$ & 1.292 \\
\hline Tip claearance (\% S) & $1.40 \%$ \\
\hline Labyrinth Seal & $0.93 \%$ \\
Clearance (\% S) & $1,000 \mathrm{~mm}$ \\
\hline Diameter & 0.85 \\
\hline Hub to tip ratio & 1.024 \\
\hline Total to Total & 53 (IGV) \\
Pressure Ratio & 52 (Rotor) \\
\hline & 88 (Stator) \\
\hline \# of blades & 56 mm (Rotor) \\
& 50 mm (Stator) \\
\hline$C$ (midspan) & 75 mm \\
\hline$S$
\end{tabular}

Table 1. Parameters of SNU Compressor 


\section{RESULTS AND DISCUSSION}

\section{Kinematics of Upstream Cavity Flow of Shrouded Stator}

Figure 3 illustrates the instantaneous colour contour distribution of axial, radial and tangential velocities and secondary velocity vectors in the upper cavity at $50 \%$ pitch, $T / T_{0}=60 \%$ in Plane $3.5 \mathrm{~b}$. At $-20 \%$ span, axial velocity is negative, but increases as the upper cavity flow moves closer to the mainstream passage flow. In addition, positive radial velocity is dominant at planes $3.5 \mathrm{a}$ and $3.5 \mathrm{~b}$ (close to rotor) and negative radial velocity is observed at Plane $3.5 \mathrm{c}$ (close to stator). This is due to the labyrinth seal leakage flow entering the upstream cavity. At first, the labyrinth seal leakage flow axially enters the upper cavity, and is turned radially. Because of this behaviour, the secondary velocity vector at the lower cavity shows clockwise distribution, with the negative axial velocity at the lower span of cavity. Nearby the mainstream passage, a vortical structure created by the cavity flow entering the mainstream passage is observed (Demargne and Longley, 2000; Wellborn, 2001). Due to this vortical structure, negative radial velocity is observed in Plane 3.5c. Finally, tangential velocity distribution inside cavity up to $\sim-10 \%$ span remains constant at about $\sim 0.36 U_{\text {tip. }}$. Near the mainstream passage region, tangential velocity increases due to the mainstream passage flow. Overall, the measured velocity contours and secondary velocity vector distributions in the upper shrouded stator cavity are consistent with those of the previous investigations.

The $3^{\text {rd }}$ stage rotor wake leads to unsteady variation of the cavity flow structure. Figure 4 shows axial, radial velocity and secondary velocity distributions of plane $3.5 \mathrm{~b}$, including both the mainstream passage and the upper cavity. A typical low $U_{x}$ region created by $3^{\text {rd }}$ stage rotor wake is visible as the low axial velocity region. In this region, increased radial velocity is also observed, due to the secondary movement of mainstream flow being pushed by the leaned $3^{\text {rd }}$ stage rotor wake (Lee, 2019). Inside the cavity region (Span $<0 \%$ ), overall egress (positive radial velocity) is observed throughout the entire cavity, except for the two local ingress (negative radial velocity) regions near 0\% span. However, these local ingresses are not caused by the stagnation pressure of downstream stator leading edge (Wellborn, 2001). These local ingresses are first created at the PS of the $3^{\text {rd }}$ stage rotor wake, and they move towards the $3^{\text {rd }}$ stage rotor wake SS before being dispersed. In addition, without the existence of $3^{\text {rd }}$ stage rotor wake, these local ingresses disappear; no ingress is observed nearby the leading edge (LE) of downstream $3^{\text {rd }}$ stage stator (Figure 5), suggesting that the local ingresses are created by the pressure side (PS) of the $3^{\text {rd }}$ stage rotor wake. The possible reason for this phenomenon is wider axial distance between the cavity and downstream stator LE. Comparing the layout of shroud between the LSAC (Wellborn and Okiishi, 1999; Wellborn, 2001) and the SNU Compressor, the axial distance of SNU Compressor is higher. Thus, the suppression of the leakage flow would be confined to nearby the downstream stator LE. In this research, the distance between each measuring plane is $1 / 6^{\text {th }}$ of the cavity axial clearances due to the shallow gap between the $3^{\text {rd }}$ rotor disk and the shroud of
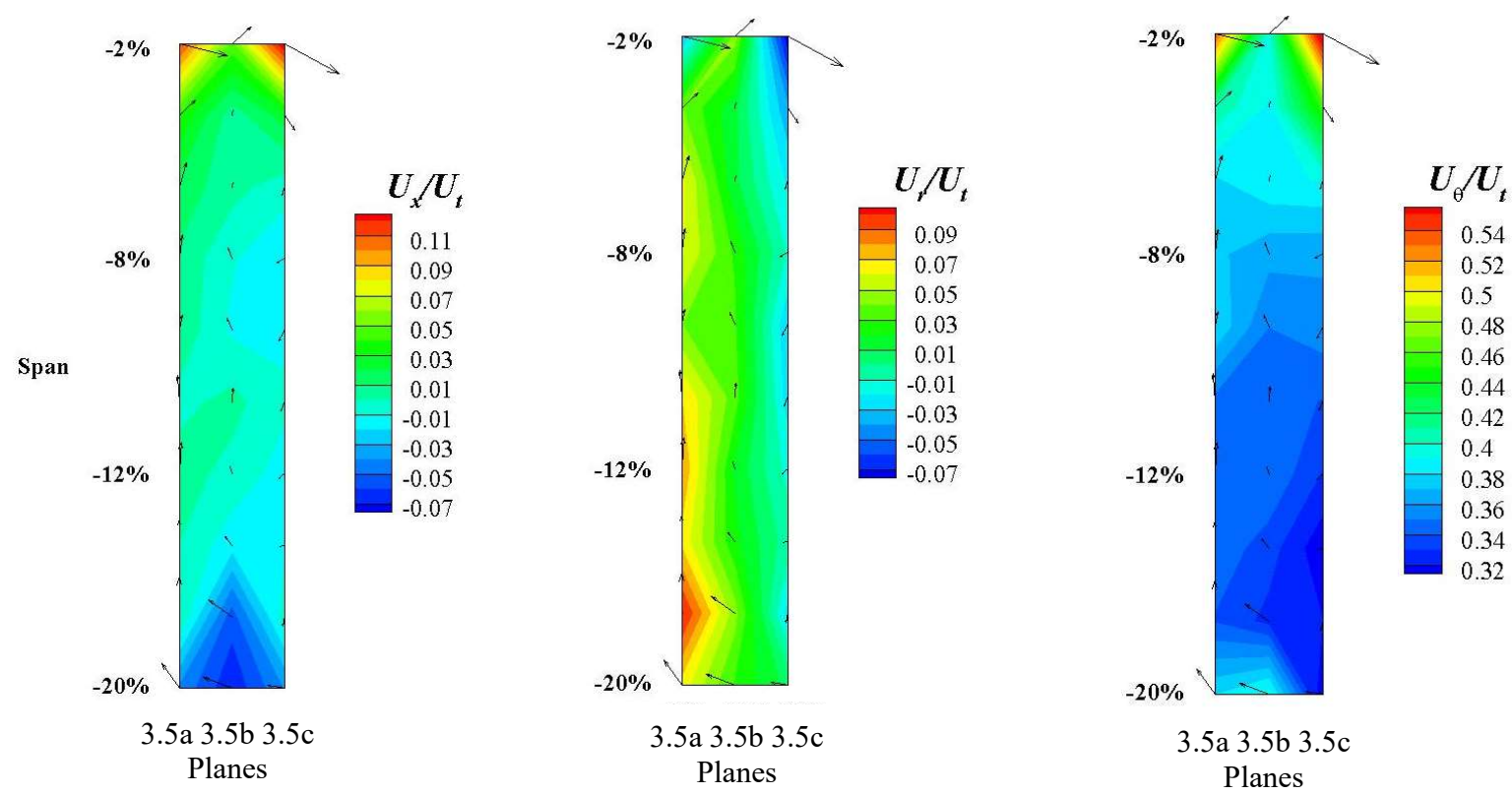

Figure 3. Axial-Radial Distributions of Ensemble-Averaged Velocity Components inside the Upper Cavity of $3^{\text {rd }}$ Stage Stator at $50 \%$ pitch, $T / T_{0}=60 \%$ 

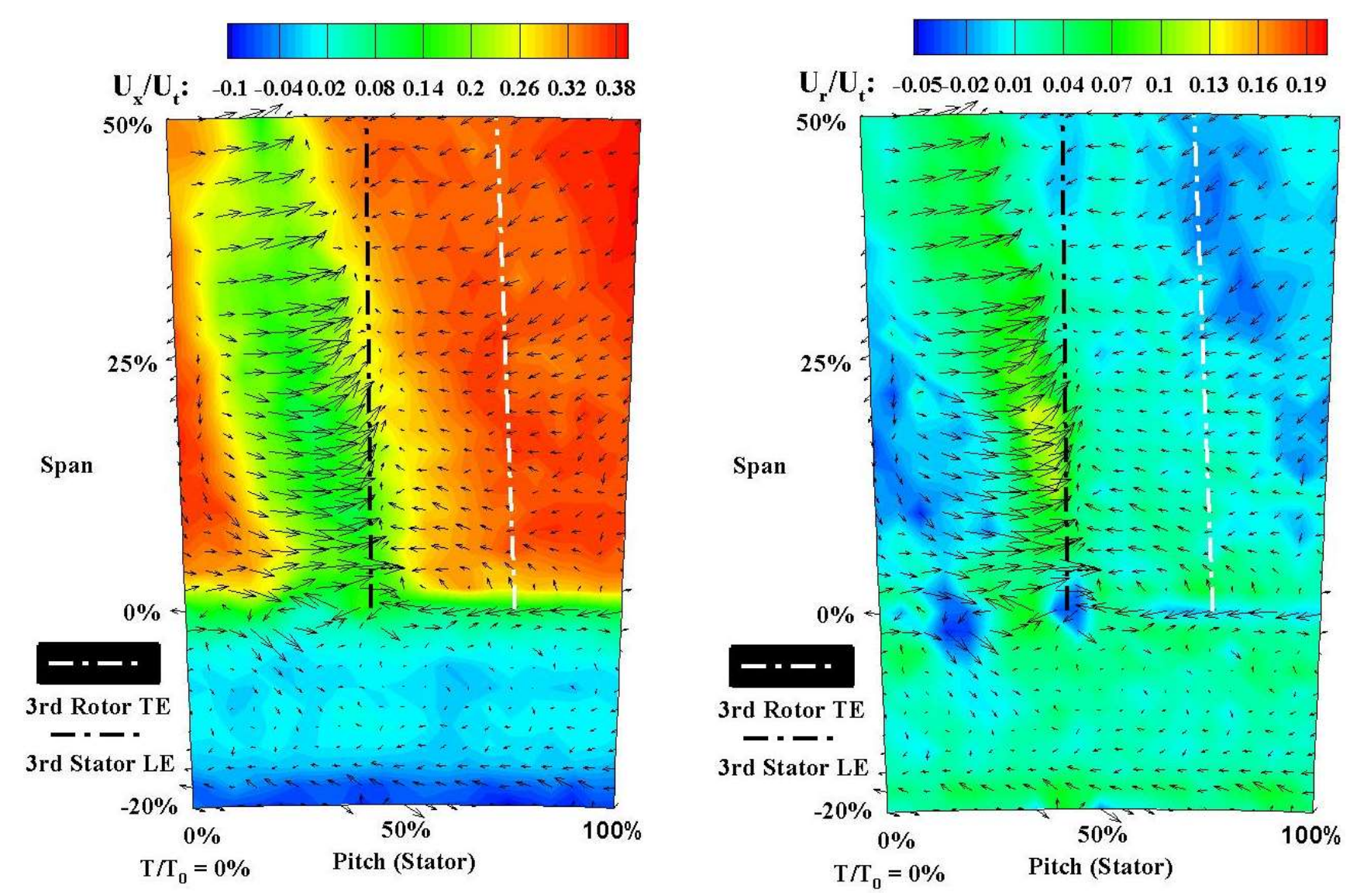

Figure 4. Ensemble-Averaged $U_{x}, U_{r}$ and Secondary Velocity Vector Distribution at Plane 3.5b, $T / T_{0}=0 \%$

$3^{\text {rd }}$ stator. Therefore, it is possible that the local ingress due to the suppression of downstream $3^{\text {rd }}$ stage stator is outside the plane $3.5 \mathrm{c}$.

The location of the local ingresses of upstream cavity show intermittent behaviour; $U_{x}$ and $U_{r}$ at different timestep $\left(T / T_{0}=25 \%\right)$ in Figure 6 showed the local egresses nearby the $3^{\text {rd }}$ stage rotor wake PS, unlike the previous timestep $\left(T / T_{0}\right.$ $=0 \%)$. In addition, high intermittent radial velocity $\left(\sim 0.18 U_{\text {tip }}\right)$ is observed at the hubside of $3^{\text {rd }}$ stage rotor PS, with its maximum at $\sim 10 \%$ span. This phenomenon is due to the multistage effect of the superposition of $3^{\text {rd }}$ stage rotor and $2^{\text {nd }}$ stator wakes (Lee, 2019). Due to the wider hubside thickness of the $2^{\text {nd }}$ shrouded stator wake hubside corner separation, the mainstream flow nearby the $3^{\text {rd }}$ stage rotor wake experiences higher hubside blockage when $2^{\text {nd }}$ stator and $3^{\text {rd }}$ stage rotor wake are superimposed. Thus, the hubside passage flow near the $3^{\text {rd }}$ stage rotor wake PS has shifted towards the midspan region, creating the hubside intermittent high positive radial velocity at hubside, creating the local egress nearby $3^{\text {rd }}$ stage rotor wake PS instead of local ingress nearby $3^{\text {rd }}$ stage rotor wake PS as shown in Figure 4. This intermittent local ingress is shifted behind the $3^{\text {rd }}$ stage rotor wake due to the $U_{\theta}$ difference between the $3^{\text {rd }}$ stage rotor wake $\left(\sim 0.7 U_{t i p}\right)$ and cavity flow $\left(\sim 0.4 U_{t i p}\right)$ and is dispersed inside the upper cavity.

These dispersions will increase the pressure loss inside the shrouded cavity flow, which will further reduce the hubside momentum of shrouded stator during the egress. Not only that, this egress of cavity flow will interact with the upstream $3^{\text {rd }}$ stage rotor wake. Thus, it is expected that the unsteady performance of shrouded stator is worse than that of steady cases, such as the unsteady simulation of Fröebel et al. (2010). Therefore, future study is required to discuss the interaction between the cavity flow and the mainstream flow of shrouded axial compressor.

\section{Kinematics of Downstream Cavity Flow of Shrouded Stator}

Figure 7 shows $U_{x}$ at plane $4.0 \mathrm{~b}$, and $U_{r}$ and secondary velocity distributions in the downstream cavity of shrouded stator at four different pitchwise positions $(0 \%, 25 \%, 50 \%, 75 \%$ of a stator pitch). A wider low-axial momentum region created by the hubside corner separation is observed, which is typical. The axial-radial distributions of downstream cavity flow show the vortical structure throughout the entire pitch, consistent with Wellborn (2001). Due to the higher axial momentum of hubside passage flow entering the downstream cavity, the passage flow first impacts the downstream rotor disk, is turned radially and enters the downstream cavity. Typical vortical structure by the passage flow entering 

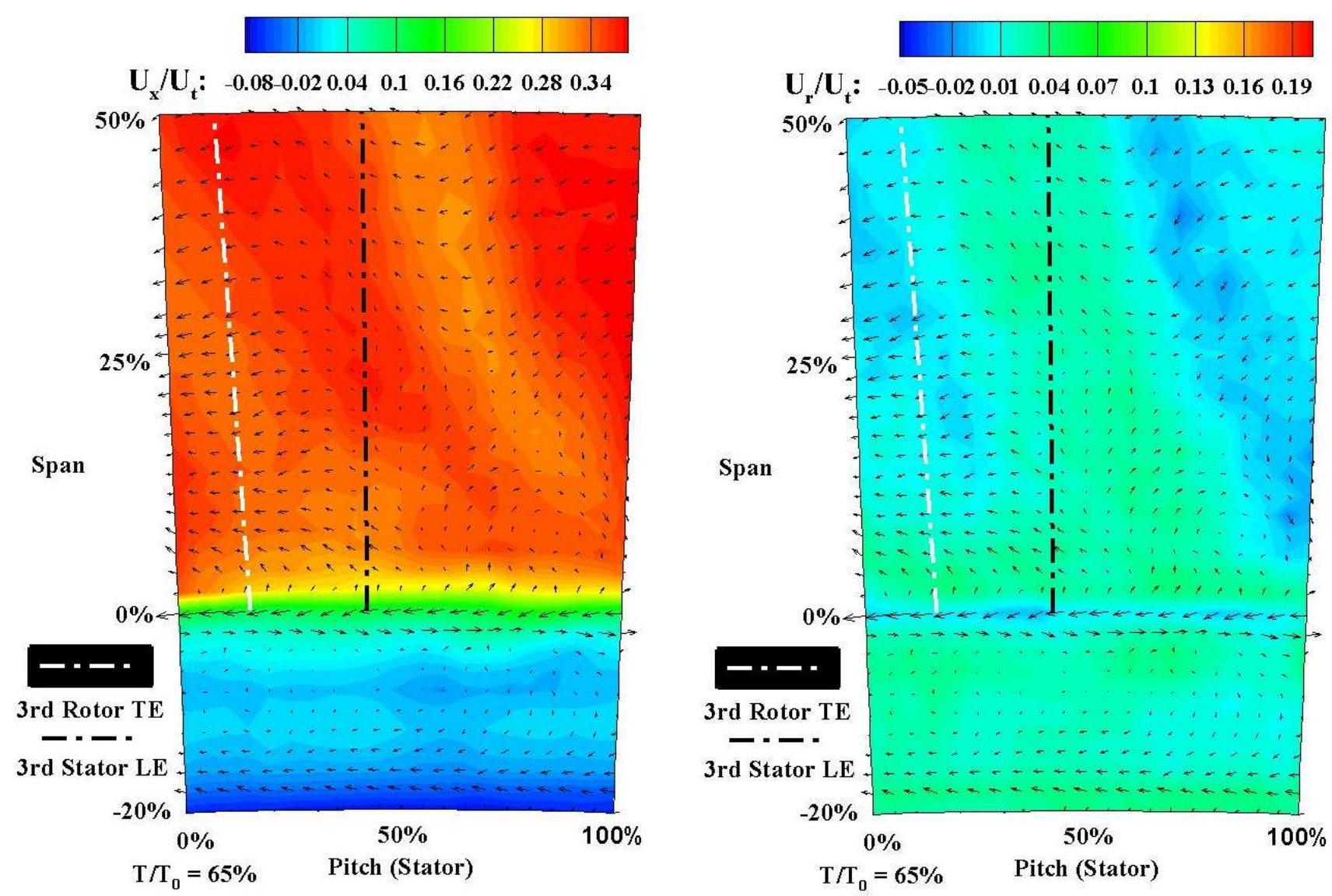

Figure 5. Ensemble-Averaged $U_{x}, U_{r}$ and Secondary Velocity Vector Distribution at Plane 3.5b, T/To $=65 \%$
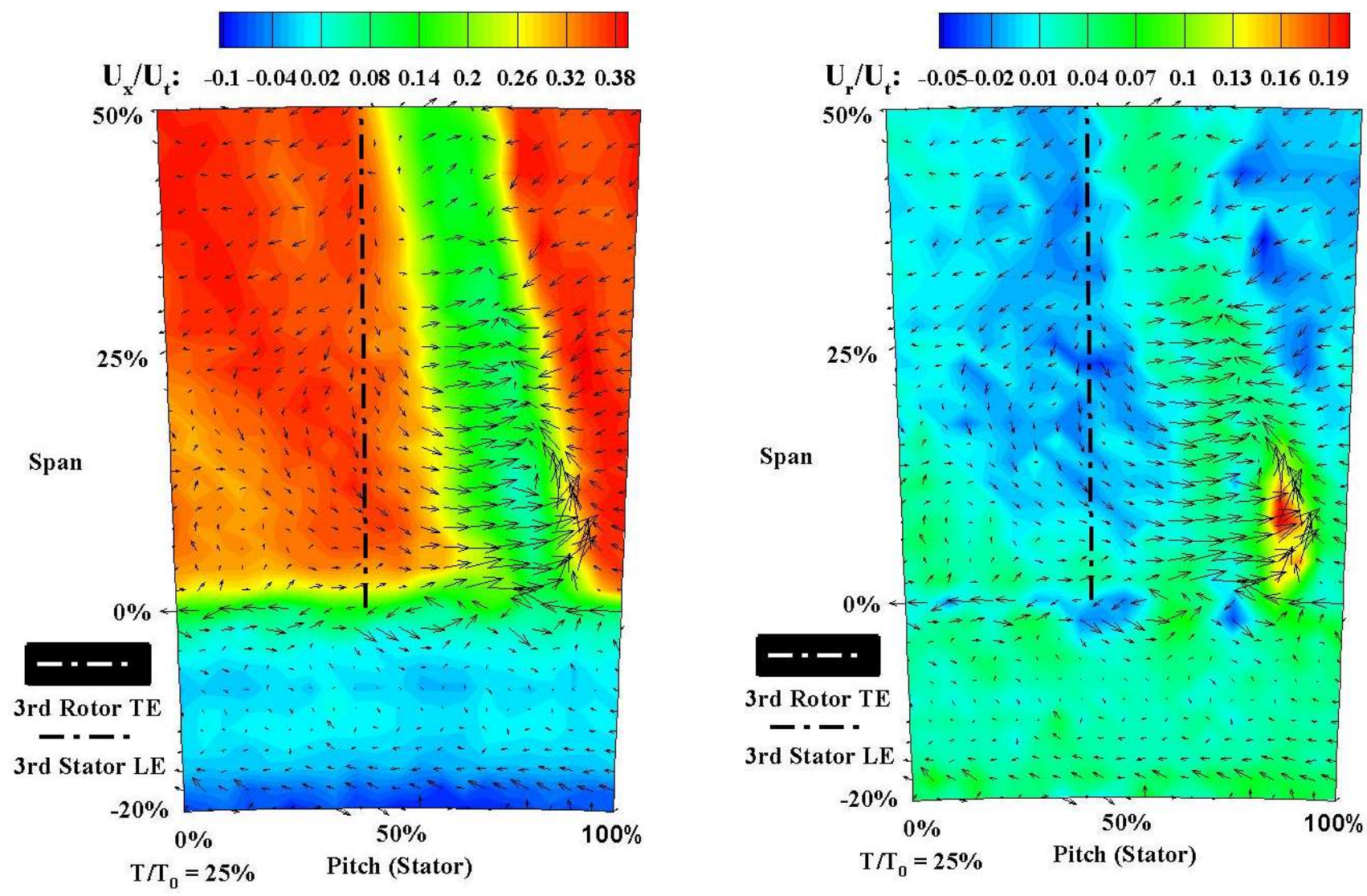

Figure 6. Ensemble-Averaged $U_{x}, U_{r}$ and Secondary Velocity Vector Distribution at Plane 3.5b, $T / T_{0}=25 \%$ 

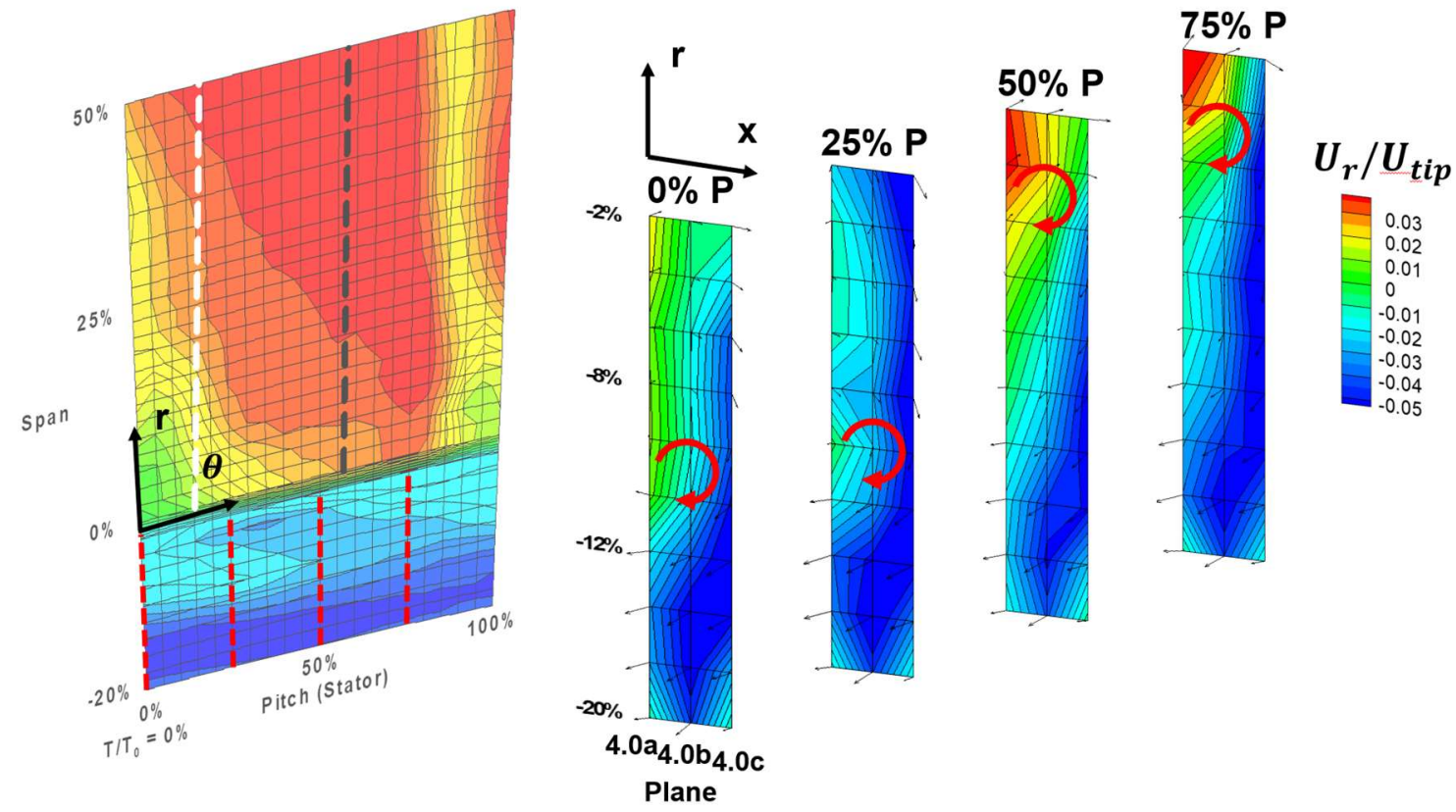

Figure 7. Ensemble-Averaged $U_{x}$ at Plane 4.0, and Pitchwise Distribution of $U_{r}$ and Secondary Velocity Distribution inside Downstream Cavity of $3^{\text {rd }}$ Stage Stator, $T / T_{0}=0 \%$

the downstream cavity is created (Wellborn, 2001).

Thus, ingress of passage flow is dominant in Plane 4.0c, and positive radial velocity is observed in Planes 4.0a and $4.0 \mathrm{~b}$ (close to stator). However, its radial location varies pitchwise; near the hubside corner separation ( $0 \%$ and $25 \%$ Pitch), the vortical structure is at $-10 \%$ span, whereas at the outside the hubside corner separation $(50 \%$ and $75 \%$ Pitch), the location shifted to $\sim-4 \%$ Span.

Figure 8 shows the timewise variation of downstream cavity radial velocity and secondary velocity distributions at $85 \%$ span (outside the hubside corner separation). Qualitatively, the downstream cavity flow at all timesteps; the ingress of mainstream flow near the $4^{\text {th }}$ rotor disk, the existence of cavity vortical structure and resulting positive radial velocity in
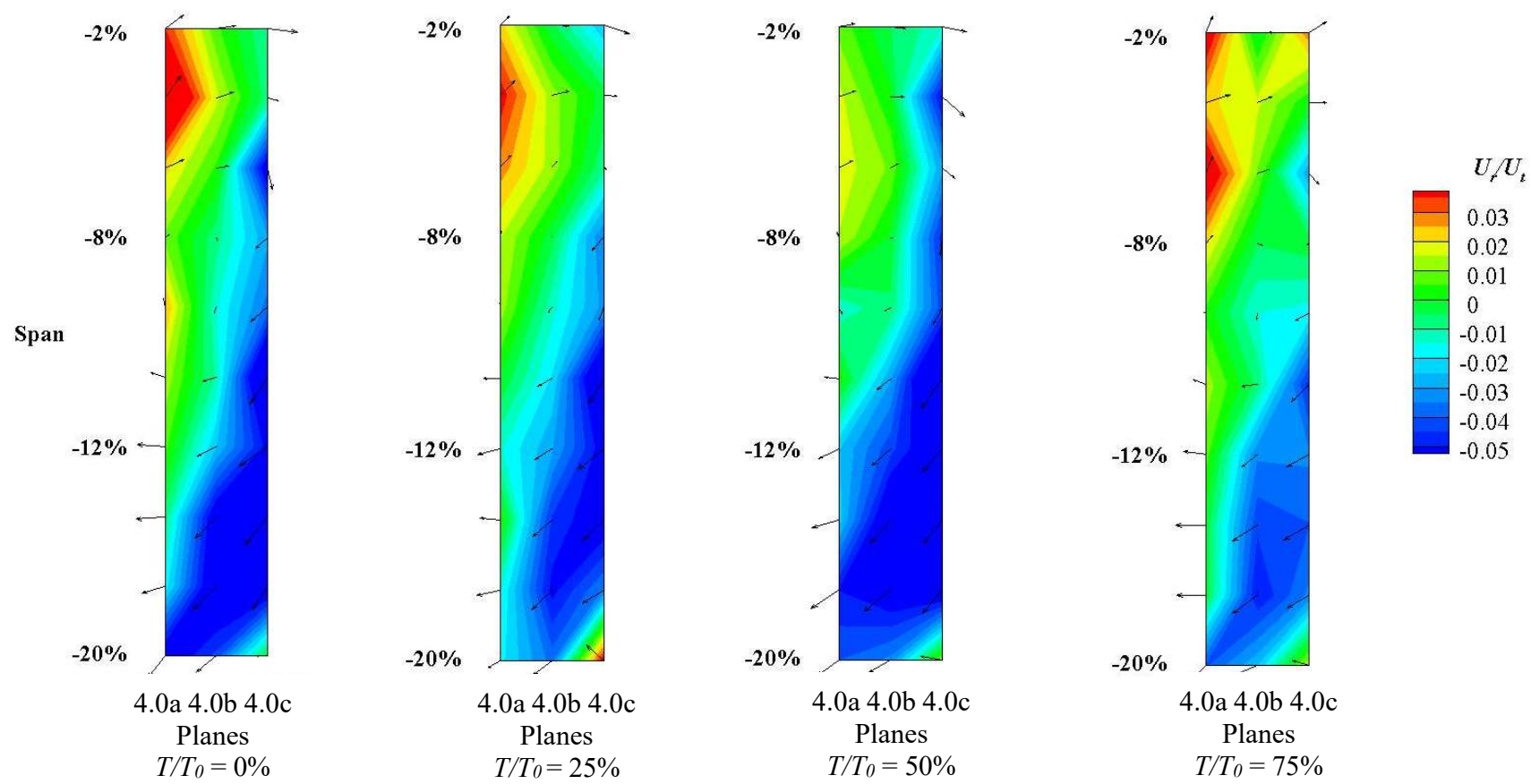

Figure 8. Ensemble-Averaged Timewise Variation of $U_{r}$ and Secondary Velocity of Downstream Cavity of $3^{\text {rd }}$ Stage Stator, $85 \%$ Span 
Plane 4.0a. The center of downstream cavity vortical structure is located at $-8 \%$ span.

However, the flow varies quantitatively with time - positive radial velocities at $T / T_{0}=25 \%$ and $50 \%$ are reduced, when $3^{\text {rd }}$ stage rotor wake is passing through the $3^{\text {rd }}$ stage stator passage (Lee, 2019). Thus, similar to the pitchwise variation of downstream cavity flow structures in Figure 6, the downstream vortical structure is affected by the reduced axial velocity.

\section{CONCLUSIONS}

The unsteady kinematics of flow shrouded cavities of a multistage shrouded axial compressor has been investigated experimentally, using single $45^{\circ}$ slanted hot-wire sensors. The measurements have identified the vortical structures within the upstream and downstream cavities due to the egress of labyrinth seal leakage flow, and the ingress of passage flow into the downstream cavity. In addition, the shrouded cavity flows are affected by the timewise variation of the mainstream flow, which is primarily induced by the $3^{\text {rd }}$ stage rotor wake entering the $3^{\text {rd }}$ stage stator passage. Specifically,

1. Intermittent local ingresses are observed inside the upstream cavity of shrouded stator. These ingresses first originate near at the PS of $3^{\text {rd }}$ stage rotor wake.

2. By the hubside radial movement due to the superposition between $3^{\text {rd }}$ stage rotor and $2^{\text {nd }}$ stator wakes, the local ingress is temporary suppressed, reverted into local ingress.

3. Pitchwise variation of downstream cavity flow structure is observed, which is created by the difference of hubside axial momentum due to the hubside corner separation of shrouded stator passage. Thus, the radial location of vortical structure varies with pitchwise location.

4. The variation of radial location of vortical structure inside the downstream cavity is observed, due to the transportation of $3^{\text {rd }}$ stage rotor wake inside the $3^{\text {rd }}$ stage stator passage.

\section{NOMENCLATURE}

Variables

$C$ Chord [mm]

$m$. mass flow rate $[\mathrm{kg} / \mathrm{s}]$

$P \quad$ Pitch

$P_{s} \quad$ Static pressure $[\mathrm{Pa}]$

$P_{t} \quad$ Total pressure $[\mathrm{Pa}]$

$r$ Radial direction [mm]

$S \quad$ Span [mm]

$T$ Time [s]

$T_{0}$ Time for 1 rotor passage rotation [s]

$U$ Velocity $[\mathrm{m} / \mathrm{s}]$

$x \quad$ Axial direction

$\phi \quad$ Flow coefficient

$\psi \quad$ Pressure coefficient

$\theta$ Tangential direction

$\dot{\theta} \quad$ Rotation speed $[\mathrm{Rad} / \mathrm{s}]$

$\rho \quad$ Density $\left[\mathrm{kg} / \mathrm{m}^{3}\right]$

$v$ Kinematic viscosity of air $\left[\mathrm{m}^{2} / \mathrm{s}\right]$

Subscripts and Abbreviations

d Design

tip Rotor tip velocity component

LE Blade leading edge

TE Blade trailing edge

PS Blade pressure side

SS Blade suction side

\section{ACKNOWLEDGMENTS}

This study is funded by the BK 21+ program of the National Research Foundation of the Republic of Korea, Seoul National University Institute of Advanced Mechanics and Design, and Doosan Heavy Industries \& Construction. The authors greatly appreciate their support. In addition, the authors would like to appreciate Dr. Hyoun-Woo Shin for his advice about the unsteady velocity measuring techniques. 


\section{References}

Campobasso, M. S., Mattheiss, A., Wenger, U., Amone, A. and Boncinelli, P. (1999). Complementary Use of CFD and Experimental Measurements to Assess the Impact of Shrouded and Cantilevered Stators in Axial Compressors. ASME Turboexpo 1999, 99-GT-208.

Childs, P. R. N. (2004). Mechanical Design 2nd Edition, Elsevier, Oxford, Great Britain.

Denecke, J., Färber, J., Dullenkopf, K. and Bauer, H. J. (2005). Dimensional Analysis and Scaling of Rotating Seals. ASME Turboexpo 2005, GT2005-68676.

Chupp, R. E., Hendricks, R. C., Lattime, S. B. and Steinetz, B. M. (2006). Sealing in Turbomachinery. Journal of Propulsion and Power, Vol. 22 (2), pp. 313-349.

Coleman, H. W. and Steele, W. G. (2009). Experimentation, Validation, and Uncertainty Analysis for Engineers $3^{\text {rd }}$ Edition, Wiley, New Jersey, USA.

Demargne, A. A. and Longley, J. P. (2000). Aerodynamic Interaction of Stator Shroud Leakage and Mainstream Flows in Compressors. ASME Turboexpo 2000, 2000-GT-570.

Flores, D. and Seume, J. R. (2014). Selecting Cavity Geometries for Improving the Aerodynamic Performance of an Axial Compressor. ASME Turboexpo 2014, GT2014-25328.

Fröebel, T., Kau, H. P., Groth, C., Gümmer, V. (2010). Numerical Investigation of Unsteady Flow Phenomena in an HP Axial Compressor Incorporating Stator Shroud Cavities. 46th AIAA/ASME/SAE/ASEE Joint Propulsion Conference \& Exhibit, AIAA 2010-6532.

Heidegger, N. J., Hall, E. J. and Delancy, R. A. (1996). Parameterized Study of High-Speed Compressor Seal Cavity Flow. AIAA Paper 96-2807.

Joslyn, H. D. and Dring, R. P. (1985). Axial Compressor Stator Aerodynamics. Journal of Engineering for Gas Turbines and Power, Vol. 107 (2), pp. 485-493. Wellborn and Okiishi, 1996,

Kerrebrock, J. L. and Mikolajczak, A. A. (1970). Intra-Stator Transport of Rotor Wakes and Its Effect on Compressor Performance. Journal of Engineering for Power, Vol. 92 (4), pp. 359-368.

Kim, J. W., Lee, J. S., Song, S. J., Kim, T. and Shin, H-. W. (2012). The Impact of Leakage Flow Tangential Velocity on Secondary Losses in a Shrouded Compressor Cascade. ASME Turboexpo 2012, GT2012-69217.

Lange, M., Mailach, R. and Vogeler, K. (2010). An Experimental Investigation of Shrouded and Cantilevered Compressor Stators at Varying Clearance Sizes. ASME Turboexpo 2010, GT2010-22106.

Lange, M., Rolfes, M., Mailach, R. and Schrapp, H. (2018). Periodical Unsteady Atip Clearance Vortex Development in a Low Speed Axial Research Compressor at Different Tip Clearances. Journal of Turbomachinery, Vol. 140 (3), 031005.

Lee, J. (2019). Experimental Study on Unsteady Kinematics of Shrouded Multistage Axial Compressor Flow. Ph. D Thesis, Seoul National University, Republic of Korea.

Mailach, R., Lehmann, I. and Vogeler, K. (2008a). Periodical Unsteady Flow Within a Rotor Blade Row of an Axial Compressor - Part I: Flow Field at Midspan. Journal of Turbomachinery, Vol. 130 (4), 041004.

Marty, J. and Aupoix, B. (2013). Interaction of Shrouded Stator Flow and Main Flow and Its Influence on Performances of a Three-Stage High Pressure Compressor. Journal of Power and Energy, Vol. 226 (4), pp. $489-500$. Heidegger et al. 1980

Pfau, A. (2003). Loss Mechanisms in Labyrinth Seals of Shrouded Axial Turbines. Ph. D Thesis. Swiss Federal Institute of Technology Zurich. Swiss Confederation.

Sanders, A. J., Papalia, J. and Fleeter, S. (2002). Multi-Blade Row Interactions ina Transonic Axial Compressor: Part I - Stator Particle Image Velocimetry (PIV) Investigation. Journal of Turbomachinery, Vol. 124 (1), pp. 10-18.

Schrapp, H., Dodegge, A., Gümmer, V., Harvey, N. W., Städing, J., Friedrichs, J. (2019). Reducing Compressor

Shroud Leakage Flows by Raising the Stator Hub Line: Low Speed Tests. ASME Turboexpo 2019, GT2019-91611.

Shin, H. W., Whitfield, C. E. and Wisler, D. C. (1994). Rotor-Rotor Interaction for Counter-Rotating Fans, Part 1:

Three-Dimensional Flowfield Measurements. AIAA Journal, Vol. 32 (11), pp.2224-2233.

Smith, L. H. (1966). Wake Dispersion in Turbomachines. ASME Journal of Basic Engineering 88 (3), 688-690.

Swoboda, M., Ivey, P. C., Wenger, U. and Gummer, V. (1998). An Experimental Examination of Cantilevered and Shrouded Stators in a Multistage Axial Compressor. ASME Turboexpo 1998, 98-GT-282.

Valkov, T. V. and Tan, C. S. (1999). Effect of Upstream Rotor Vortical Disturbances on the Time-Averaged Performance of Axial Compressor Stators: Part 1-Framework of Technical Approach and Wake-Stator Blade Interactions. Journal of Turbomachinery, Vol. 121 (3), pp. 377-386.

Wellborn, S. R. and Okiishi, T. H. (1999). The Influence of Shrouded Stator Cavity Flows on Multistage Compressor Performance. Journal of Turbomachinery, Vol. 121 (3), pp. 486-497. Wellborn, 1999,

Wellborn, S. R. (2001). Details of Axial-Compressor Shrouded Stator Cavity Flows. ASME Turboexpo 2001, 2001GT-0495.

Yoon, S., Selmeier, R., Cargill, P., Wood, P. (2014). Effect of the Stator Hub Configuration and Stage Design Parameters on Aerodynamic Loss in Axial Compressors. ASME Turboexpo 2014, GT2014-26905. 